\section{Carpe covid: using COVID-19 to communicate about harms of tobacco products}

\author{
Lucy Popova
}

Many of us in the field of tobacco control have asked how the COVID-19 pandemic can be used as an opportunity to motivate people to quit using tobacco products. A paper by Grummon et $a l^{1}$ (this issue) is, to my knowledge, the first published attempt to empirically answer this question. Emerging research consistently demonstrates that smoking makes COVID-19 outcomes worse, ${ }^{2}$ although the relationship between smoking and COVID-19 infection is unclear. A recent study showed cross-sectional association between youth and young adult e-cigarette use and COVID-19. ${ }^{3}$ Thus, more research is needed on how to best inform tobacco users about the increased risk of COVID19. Grummon et $a l^{1}$ answer this call by evaluating messages that inform smokers and e-cigarette users (vapers) how smoking or vaping may increase the severity of COVID-19.

Grummon et al ${ }^{1}$ (this issue) conducted two online experiments (one on smoking and one on vaping) in May 2020 with a national convenience sample of 810 US adults who were current smokers and/or current vapers. Stimuli were messages in the form of tweets from the Centers for Disease Control and Prevention (CDC). The messages combined information about harms of smoking or vaping and detrimental effects of smoking or vaping on susceptibility and severity of COVID-19 (becoming infected with COVID-19, being hospitalised from COVID-19, and dying from it).

Results of the smoking experiment showed that messages on harms of smoking both with and without COVID-19 information were perceived as more effective at discouraging participants from smoking than a control message. In the vaping experiment, only messages with traditional harms were perceived as more effective, and the messages about COVID-19 harms did not increase the perceived message effectiveness. In both

School of Public Health, Georgia State University, Atlanta, Georgia, USA

Correspondence to Dr Lucy Popova, School of Public Health, Georgia State University, Atlanta, GA 303023965, USA; Ipopova1@gsu.edu experiments, messages with different types of harms (single or multiple harms; harm to immune function, lung function or heart disease) were perceived at roughly the same level of effectiveness. A similar pattern of results held for secondary outcomes, such as attention to the message, cognitive elaboration, negative affect, and perceived harm, among others. For smoking and COVID-19 messages tested in this study, their content was congruent with the information smokers have heard again and again-that smoking is not healthy. For vaping messages, the information might have been novel and not part of the broader discussion, which could explain the lack of higher perceived effectiveness for COVID-19 messages for vaping without mention of other, more traditional harms.

Several things about this study deserve commendation: registering the study and planned analyses ahead of time (which is rarely done in message research) and providing exhaustive supplemental tables with all the information needed (a joy to a reviewer and a discerning reader!). The consistent pattern of findings for perceived message effectiveness and emotional reactions, attention, and beliefs about harm, which are precursors to behaviour, give confidence that the messages would have similar influence on behaviour.

The lack of measurement of actual behaviour or behavioural intentions is not an issue. It is unlikely that exposure to a single message will change behaviour or even behavioural intentions-and that is not how messaging campaigns work. The messages exert their influence in the context of the larger communication environment and other messages that circulate there.

Agencies around the world and in the USA, such as the World Health Organization, the CDC, and the National Cancer Institute, have already started using the messages about smoking and COVID-19. The next step is to evaluate whether these messages might motivate tobacco users to try quitting. Evidence on the effects of the COVID-19 pandemic on smoking cessation has been mixed: worldwide Google searches for 'quit smoking' did not change from January to April 2020, ${ }^{4}$ and among smokers, some report smoking less, others report more. ${ }^{5}$ In the UK, the early COVID-19 lockdown did not reduce smoking rates, but was associated with increased quit attempts and successful cessation. ${ }^{6}$ Research on how vaping behaviour might have changed during the COVID-19 pandemic is even scanter but urgently needed.

This study is the first to examine this rich area, with many questions ready for future investigations. Grummon et $a l^{1}$ examined short, Twitter-like messages, but what effects might other messages have, such as those reported in the news or in the form of traditional public service announcements? Even though messages with COVID-19 were not viewed as more effective in a setting of a controlled study where participants had to read the messages, would they be more effective in the real world where they might be more likely to attract attention in an overcrowded media environment and more likely to be talked about and retweeted? The study was conducted in May, still in the early stages of COVID-19. Would the findings be similar at the later stage of the pandemic? Is it possible that smokers might get fatigued not only about smoking messages but also about COVID-19 messages?

The COVID-19 pandemic shows little signs of abating any time soon. We should turn this adversity into an opportunity and seize it to fight the ongoing pandemic of tobacco use.

\section{Contributors LP wrote and edited this article.}

Funding The authors have not declared a specific grant for this research from any funding agency in the public, commercial or not-for-profit sectors.

\section{Competing interests None declared,}

Patient consent for publication Not required.

Provenance and peer review Commissioned; internally peer reviewed.

This article is made freely available for use in accordance with BMJ's website terms and conditions for the duration of the covid-19 pandemic or until otherwise determined by BMJ. You may use, download and print the article for any lawful, non-commercial purpose (including text and data mining) provided that all copyright notices and trade marks are retained.

(c) Author(s) (or their employer(s)) 2020. No commercial re-use. See rights and permissions. Published by BMJ.

$$
\text { D Check for updates }
$$

To cite Popova L. Tob Contro/ Epub ahead of print: [please include Day Month Year]. doi:10.1136/ tobaccocontrol-2020-056276

CLlinked 


\section{Editorial}

- http://dx.doi.org/10.1136/tobaccocontrol-2020055956

Tob Control 2020:0:1-2.

doi:10.1136/tobaccocontrol-2020-056276

ORCID iD

Lucy Popova http://orcid.org/0000-0002-3450-4579

\section{REFERENCES}

1 Grummon AH, Hall MG, Mitchell CG. Reactions to messages about smoking, vaping, and COVID-19: two national experiments. Tob Control 2020.

2 Reddy RK, Charles WN, Sklavounos A, et al. The effect of smoking on COVID-19 severity: a systematic review and meta-analysis. J Med Virol 2020;16.

3 Gaiha SM, Cheng J, Halpern-Felsher B. Association between youth smoking, electronic cigarette use, and COVID-19. J Adolesc Health 2020;67:519-23.

4 Heerfordt C, Heerfordt IM. Has there been an increased interest in smoking cessation during the first months of the COVID-19 pandemic? A Google trends study. Public Health 2020;183:6-7.

5 Bommele J, Hopman P, Walters BH, et al. The doubleedged relationship between COVID-19 stress and smoking: implications for smoking cessation. Tob Induc Dis 2020;18:63.

6 Jackson SE, Garnett C, Shahab L, et al. Association of the COVID-19 lockdown with smoking, drinking, and attempts to quit in England: an analysis of 2019-2020 data. Addiction 2020. doi:10.1111/add.15295. [Epub ahead of print: 21 Oct 2020] 